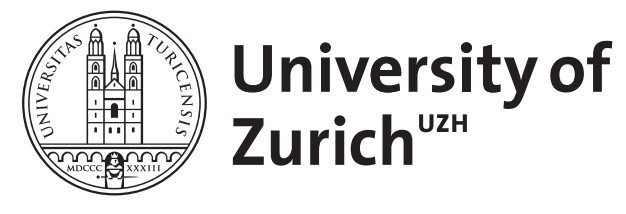

\title{
Federal Stability in Unequal Societies
}

Hug, Simon

\begin{abstract}
The stability of federal systems is a thorny issue. Several scholars have attempted to come to grips with this problem and have proposed mechanisms or institutions which may contribute to the stabilization of federal systems. In many instances, however, the underlying mechanisms and microfoundations are poorly specified. In this paper I build upon existing models dealing with decentralization and secession to incorporate unequal income distributions and externalities of public goods. Based on this some insights may be derived on the appropriate mechanisms to foster federal stability
\end{abstract}

DOI: https://doi.org/10.1007/s10602-005-2231-9

Posted at the Zurich Open Repository and Archive, University of Zurich ZORA URL: https://doi.org/10.5167/uzh-155811

Journal Article

Published Version

Originally published at:

Hug, Simon (2005). Federal Stability in Unequal Societies. Constitutional Political Economy, 16(2):113124.

DOI: https://doi.org/10.1007/s10602-005-2231-9 


\title{
Federal Stability in Unequal Societies ${ }^{1}$
}

SIMON HUG

simon.hug@access.unizh.ch

Universität Zürich, 8001 Zürich, Switzerland

\begin{abstract}
The stability of federal systems is a thorny issue. Several scholars have attempted to come to grips with this problem and have proposed mechanisms or institutions which may contribute to the stabilization of federal systems. In many instances, however, the underlying mechanisms and microfoundations are poorly specified. In this paper I build upon existing models dealing with decentralization and secession to incorporate unequal income distributions and externalities of public goods. Based on this some insights may be derived on the appropriate mechanisms to foster federal stability.
\end{abstract}

JEL Classification: H77, H41, C72

Key words: federalism, income, distribution, secession

\section{Introduction}

Few scholars would contest that federal systems may suffer from a lack of stability. Hicks's (1978) and Watts's (1998) lists of failed federal systems serve as sufficient empirical illustration, and several prominent theoretical arguments (e.g., Riker 1964, 1996; Bednar 1997; Kollman and Page 1997; Filippov et al. 2004) underline this point. Thus, a major challenge to scholars of federalism is to elucidate what may contribute to the stability of federal systems.

Several scholars have attempted to provide answers to this question. Riker (1964), for instance, had the hunch that political parties played an important role in assuring federal stability. This element is elaborated upon by Ordeshook and Shvetsova (1997) and Filippov et al. (2004) in more detail. McGarry and O'Leary (2003), analyzing a set of federal systems, come to the conclusion that some sort of power-sharing and consociational arrangements make federalism stable. ${ }^{2}$ Bednar (2004) on the other hand, and following on the literature relating federalism with constitutional review (e.g., Lijphart 1999), emphasizes the role of the judiciary in upholding the federal bargain.

While some of these attempts rely largely on generalizations (e.g., Gurr 2000; McGarry and O'Leary 2003), ${ }^{3}$ others aim at providing micro-foundations with the help of theoretical models. While these models inform us at least in part on some elements which may strengthen the stability of federal arrangements, many elements and links still have to be uncovered.

In this paper I propose to build upon Alesina and Spolaore's (2003) model of political and economic integration, ${ }^{4}$ to elucidate some aspects of federal stability. More precisely, I try to assess the effects of differences in average income between 
regions and externalities, elements largely neglected in Alesina and Spolaore (2003). As I am able to show, income differences make secession a very attractive option for richer regions in a federal system. Only if negative externalities of secession offset these advantages do income differences not encourage secession. Before presenting these results I will discuss in the next section the main arguments concerning the elements which may strengthen federal stability. In section three I present several models which deal either directly or indirectly with the issue of federal stability. Section four is devoted to the discussion of extensions to Alesina and Spolaore's (2003) model, while section five offers some concluding remarks and an outlook for further work.

\section{Enhancing Federal Stability}

The most challenging task in research on federal systems is certainly determining the mechanisms that might enhance the stability of these arrangements. The seminal work by Riker (1964) was clearly already preoccupied by this important question. His analytical approach suggested that political parties, and the way in which the latter were organized and integrated in federal systems, could contribute to federal stability. What many subsequent authors (e.g., Filippov et al. 2004) noted, however, was that the mechanisms underpinning these arguments were largely unspecified.

Similarly, in the inductive approach used by McGarry and O'Leary (2003) the exact mechanisms which might make consociationalism a good addition to federal systems are left unspecified. ${ }^{5}$ In their research they simply try to assess what distinguishes federal systems that survived from those that failed to do so. According to McGarry and O'Leary (2003) the most discriminating feature between these two sets of federal systems is the presence of consociational features. In the absence of a clear theoretical understanding of the mechanisms leading consociational elements to contribute to federal stability, however, this claim has to be taken with some reservation.

More promising in this respect appear formal approaches which attempt to sketch out precisely the mechanisms making federal systems more stable. For instance, Filippov et al. (2004) provide theoretical elements going beyond Riker's (1964) original claim. In their theoretical model the driving force is the degree to which politicians pursue the interests of their regionally based voters, or whether they may differ from this mandate. In the latter case, federal stability is better assured.

Similarly, Bednar (2004) offers a theoretical model which demonstrates in much detail under what circumstances supreme courts may contribute to federal stability. This is a welcome contribution to the largely descriptive arguments appearing in the literature. ${ }^{6}$

While these theoretical models make important contributions to our understanding of the mechanisms allowing for or contributing to federal stability, many questions 
still remain. Some answers to these questions may be found in more general models dealing with economic and political integration (e.g., Alesina and Spolaore 2003) or work on secession (e.g., Young 1998).

\section{Models of Federal Stability}

The most dramatic challenge to a federal system is obviously the secession of parts of its territory. Young (1998) offers a brief discussion of this literature and analyses some very simple games of secession. A drawback of most of the models (largely two-by-two normal form games) Young (1998) discusses is that they hardly allow for assessing institutional elements which might make secession less likely. More promising along these lines are explicit models of secession, like for instance the work by Bolton and Roland (1997) and Bordignon and Brusco (2001). The latter authors especially focus on the optimal secession rules which constitutions should contain.

An important tension in this respect is discussed by Alesina and Spolaore (2003). In their model of political and economic integration they are able to determine the optimal size of nations from the perspective of a welfare-maximizing social planner. In this "optimal world," however, individuals living at the periphery of an entity are tempted to secede. ${ }^{7}$ When "voting on borders" is possible Alesina and Spolaore (2003, 31-52) find that the number of nations is most often larger and thus sub optimal. "Voting on borders" is obviously nothing else than secession in this case. Secession might be staved off by paying individuals living on the fringes of a nation some transfer payments. But the question then arises, as Alesina and Spolaore (2003) show and Dudley (2004) discusses, what will make government stick to its promise to continue paying transfers once secession has been staved off. This tension offers a nice example of the commitment problems that are of central importance in federal systems (e.g., Bednar 1997; Bednar et al. 2001).

While building on a model like Alesina and Spolaore's (2003) already allows for some important insights concerning federal stability, some limitations should not be forgotten. Three elements seem to be crucial. First, as Besley and Coate (2003) clearly show the assumption that public goods have to be distributed uniformly in centralized systems is hardly an accurate starting point to assess the merits of federal and centralized systems. Even in centralized states a public good, e.g., a bridge, will benefit mostly a particular region and not the entire nation. Second, Besley and Coate (2003) also stress the importance of spillovers in the provisions of public goods. Finally, also the assumption of a uniform distribution of economic wealth or income may be misleading when assessing federal stability and secession in a model of political integration.

Thus, in their model Besley and Coate (2003) find that under the assumption of spillover effects of public goods and unequal regions, the tradeoff between centralization and decentralization becomes much more complex. ${ }^{8}$ Again, this seems to suggest that issues of federal stability relate closely to differences in preferences, resources and potential spillovers of public goods. 


\section{Unequal Societies and Federalism in a Model of Political Integration}

While limited by some constraining assumptions, Alesina and Spolaore (2003) still provide an interesting framework to analyze various issues related to federalism, even though their chapter on this topic is rather short. An interesting result in that regard is that democratically defined borders are sub optimal, i.e., there are too many nations, provided that transfer-payments are not possible to stem secession. By extension, this must also hold for the number of units in a federal system. The authors in their chapter on federalism (or elsewhere in their book) do, however, not address this issue directly. Their analysis of federalism in addition suffers from two constraining assumptions. On the one hand the continuous nature of preferences over public goods stands in contrast to the lumpy clusters of preferences which most certainly exist in multiethnic, multireligious, multinational etc. societies. ${ }^{9}$ Related to this, the resources and thus income is hardly distributed uniformly across the whole territory, as is implicit in Alesina and Spolaore's (2003) analyses. Especially when dealing with regional differences, supposedly to be solved by federal arrangements, not only tastes for public goods may differ across space, but incomes and available resources as well. ${ }^{10}$

On the other hand, as Besley and Coate (2003) clearly show, the exclusion of spillover effects may question many conclusions of Alesina and Spolaore (2003). This omission may surprise to some degree, since Alesina and Spolaore (2003, 140) discuss externalities in the introduction to their chapter on federalism.

Thus, in what follows I alter Alesina and Spolaore's (2003) model to allow for income differences between regions and externalities. First I will sketch Alesina and Spolaore's (2003) model and show how I introduce unequal incomes in their model. I then present results showing how differences in income affect incentives for secession and changes in the provision of public goods. Finally, I will show how externalities affect the conclusions reached under the assumption of income differences but no spillover effects.

Alesina and Spolaore's (2003) model assumes that individuals can be placed on a real line $[A, C]$ (with $A=0$ and $C=1$ ) and their position reflects their tastes for public goods. Public goods are produced at points on the same real line reflecting their characteristics. Thus, individuals prefer ceteris paribus public goods produced closer to their location on the real line. Apart utility from public goods, individuals also have a common income $y$ and pay a uniform tax $t$.

To introduce income differences between regions in this model I assume that in the entity defined by the real-line $[A, C]$ (with $A=0$ and $C=1$ ) average income equals $\bar{y}=\int^{C} y_{i} d i$. This entity is divided by $B \in[A, C]$. in two regions with possibly different average incomes. Average income in region 1 is equal to $\int y_{i} d i=\overline{y^{1}}$, while in region 2 it equals $\int_{B}^{C} y_{i} d i=\overline{y^{2}}$. Without loss of generality I assume that $\overline{y^{2}} \leq \bar{y} \leq \overline{y^{1}}$.

This change in the basic setup of Alesina and Spolaore's (2003) model requires a second change related to the issue of taxation. Alesina and Spolaore (2003) assume 
per capita taxes, which in the context of equal incomes have a direct equivalent in a proportional tax, Thus, 1 assume that a proportional tax $t$ is perceived on income, instead of a per capita tax as in Alesina and Spolaore (2003), if only one public good (a) is provided the change to a proportional tax rate results in the following utility for individual $i:{ }^{11}$

$$
u_{i}=y_{i}(1-t)+g-a_{a} l_{i}
$$

In this equation $l_{\mathrm{i}}$ corresponds to the distance between individual $i$ and the location where the public good is provided, thus reflecting differences in preferences. $a$ reflects the extent to which individuals experience disutility from public goods provided "away" from their ideal point, while g represents the utility of the public good provided. ${ }^{12}$ Thus, average utility in a territorial unit $[\mathrm{A}, \mathrm{C}]$ equals:

$$
\bar{u}=\bar{y}(1-t)+g-a \int_{A}^{C} l_{i} d i
$$

In a situation where two public goods ( $a$ and $b$ ) are provided, possibly at different levels of jurisdictions like in federal systems, the utility for individual $\mathrm{i}$ is equal to:

$$
u_{i}=y_{i}(1-t)+g-a_{a} l_{a i}-a_{b} l_{b i}
$$

\subsection{Unequal Incomes, Federalism, and Secession}

Under the assumptions of a proportional tax and possibly income differences between two regions, I assess how different types of public good provisions and financing affect tax rates and average income in the two regions. To assess these differences, I consider four scenarios about how two public goods $j(j \in\{a, b\})$ are financed ${ }^{13}$ and provided. $N_{j}$ indicates in how many jurisdictions good $j$ is provided. In scenario (i) $N_{\mathrm{a}}=N_{\mathrm{b}}=1$ thus both goods are centrally provided and financed with a uniform tax rate, In scenario (ii) I assume that $N_{\mathrm{a}}=1$ and $N_{\mathrm{b}}=2$ while the public goods are still financed through a uniform tax rate. ${ }^{14}$ Scenario (iii) is identical to the previous one, except that financing public good $b$ is done at the local level. Finally, in scenario (iv), which might be dubbed secession, $N_{\mathrm{a}}=N_{\mathrm{b}}=2$ and both goods are financed at the local level.

I analyze these four scenarios under the assumption that the lower level jurisdictions perfectly match the differences in income. ${ }^{15}$ To compare the effects of income differences I will assess whether the tax rates and average paid taxes change in the richer and poorer region. I do so because these are the only differences compared to the results obtained under the original assumptions from Alesina and Spolaore's (2003) model. In addition, I will also determine whether the average utility in the richer and poorer region increases from one scenario to the next. 
Scenario (i) Under this scenario the provision of the two public goods $j \in\{a, b\}$ with fixed $k_{j}$ and size-depending varying $\gamma_{j}$ costs will generate the total costs $c=k_{a}+k_{b}+\gamma_{a}+\gamma_{b}$. These costs are financed through taxes $t \times \bar{y}$, thus the tax rate is equal to $t=\frac{k_{a}+k_{b}+\gamma_{a}+\gamma_{b}}{\bar{y}}$. Compared to Alesina and Spolaore's (2003) model there appears no difference in the utility gains from the two public goods.

Scenario (ii) In this scenario taxes are still perceived centrally, but $N_{a}=1$ and $N_{b}=2$. In that case the costs for providing the two goods are $c=k_{a}+2 \times k_{b}+\gamma_{a}+\gamma_{b}$. Thus, the tax rate increases to $t=\frac{k_{a}+2 \times k_{b}+\gamma_{a}+\gamma_{b}}{\bar{y}}$ an increase compared to scenario (i) of $\frac{k_{b}}{\bar{y}}$ in both regions. This increase in the tax burden can only be optimal if the provision of public good $b$ in the two regions makes individuals better off, because it can be better targeted to their preferences.

The average disutility from public good $b$ under scenario $(i)$ for individuals in the richer region $(i \in[A, B])$ is equal to $a_{a} \frac{1-B}{2}+a_{b} \frac{1-B}{2}$, while it decreases to $a_{a} \frac{1-B}{2}+a_{b} \frac{B}{4}$ under scenario (ii). Thus,individuals in the richer jurisdiction are on average better off under scenario (ii) if $a_{b} \frac{2-3 B}{4}>k_{b} \frac{\overline{y_{1}}}{\bar{y}}$ where the latter part of the equality corresponds to the average tax increase. Quite clearly, the richer region is more likely to be better off under scenario (ii) if the region is rather small (small B) and if its average income $\overline{y^{1}}$ is not too high.

In the second jurisdiction $(i \in[B, C])$ the average disutility is $a_{a} \frac{1+(1+2 B)^{2}}{8(1-B)}+a_{b} \frac{1+(1+2 B)^{2}}{8(1-B)}$ in scenario $(i)$ but decreases to $a_{a} \frac{1+(1+2 B)^{2}}{8(1-B)}+a_{b} \frac{1-B}{4}$ in scenario (ii) Thus the disutility decreases by $a_{b} \frac{B^{2}}{4(1-B)}$ which has to offset the increased tax burden of $k_{b} \frac{y^{2}}{\bar{y}}$ for the poorer region to be better off. Thus, the poorer region is more likely to be better off under this scenario if the richer region is large (B larger) and its average income $\overline{y^{2}}$ is not too high.

Scenario (iii) In this scenario the tax rates differ between the two jurisdictions, Let $t^{k}=t_{a}+t_{b}^{k}$ where $t_{a}$ is the centrally perceived tax to finance public good $a$, while $t_{b}^{k}$ is the tax rate used to finance public good $b$ in jurisdiction $k$. Following from above, the common tax rate to finance public good $a$ at the central level is obviously $t_{a}=\frac{k_{a}+\gamma_{a}}{\bar{y}}$ while the tax rate to finance public good $b$ in jurisdiction 1 is $t_{b}^{1}=\frac{k_{b}+\gamma_{b} B}{\overline{y^{1}} B}$. Thus the total tax rate in jurisdiction $j=1$ is $t^{1}=\frac{k_{a}+\gamma_{a}}{\bar{y}}+\frac{k_{b}+\gamma_{b} B}{\bar{y}^{1} B}$.

Comparing this tax rate to the one obtained in scenario (ii) suggests that decentralized taxation makes jurisdiction 1 better off regarding taxes if

$$
\frac{k_{a}+2 \times k_{b}+\gamma_{a}+\gamma_{b}}{\bar{y}}>\frac{k_{a}+\gamma_{a}}{\bar{y}}+\frac{k_{b}+\gamma_{b} B}{\overline{y^{1}} B}
$$

or after some straightforward simplifications:

$$
\frac{2 \times k_{b}+\gamma_{b}}{\bar{y}}>\frac{k_{b}+\gamma_{b} B}{\overline{y^{1}} B}
$$

Multiplying through and noting that $2 \times k_{b} \overline{y^{1}}+\gamma_{b} \overline{y^{1}}-\gamma_{b} \bar{y}>0$ implies that 


$$
B>\frac{K_{b} \bar{y}}{2 \times k_{b} \overline{y^{1}}+\gamma_{b}\left(\overline{y^{1}}-\bar{y}\right)}
$$

Inspecting equation (6) suggests that if there are no income differences between the two jurisdictions (i.e., $\bar{y}^{1}=\bar{y}$ ) then $\mathrm{B}$ has to exceed $\frac{1}{2}$. But given that in Alesina and Spolaore's (2003) framework the jurisdictions are of equal size, this implies that decentralized taxation is not preferred from a tax perspective under the assumption of equal incomes. If incomes differ between jurisdictions, however, then for rich and sufficiently large regions (i.e., $B$ sufficiently close to $\frac{1}{2}$ ) decentralized taxation is preferable from a tax perspective. For given income differences it is also apparent that the required size of the richer jurisdiction to profit from decentralized taxation decreases as the fixed costs $\left(\mathrm{k}_{b}\right)$ and the varying $\operatorname{costs}\left(\gamma_{\mathrm{b}}\right)$ of providing public good $b$ increase.

In this scenario the average change in utility due to changes in tax $k_{b}\left(\frac{1}{B}-\frac{2 y^{\overline{1}}}{\bar{y}}\right)+\gamma_{b}\left(1-\frac{\overline{y^{1}}}{\bar{y}}\right)$ has to be negative, since compared to scenario (ii) the provision of the two public goods remains unaltered. This implies that the richer region is more likely to be better off under scenario (iii) if $\mathrm{B}$ and $\overline{y^{1}}$ are relatively large.

Similarly, for the poorer jurisdiction the change in the tax rate will equal $k_{b}\left(\frac{1}{\overline{y^{2}}(1-B)}-\frac{2}{\bar{y}}\right)+\gamma_{b}\left(\frac{1}{\bar{y}^{2}}-\frac{1}{\bar{y}}\right)$. Thus, $k_{b}\left(\frac{1}{(1-B)}-\frac{2 \bar{y}^{2}}{\bar{y}}\right)+\gamma_{b}\left(1-\frac{\overline{y^{2}}}{\bar{y}}\right)$ has to be negative for the poorer jurisdiction to be on average better off. This is more likely if $B$ tends to be small and $\overline{y^{2}}$ large.

Compared to Alesina and Spolaore's (2003) analyses income differences may raise demands for decentralized taxation in cases where equal incomes would have not lead to such demands in richer jurisdictions. But obviously, the other side of the coin is that the poorer jurisdiction would have to levy higher taxes to provide the same public good, especially, because the poorer jurisdiction is assumed to be larger. As the analyses show this might still be preferable on average, provided the richer region is rather small. But exactly this same affect would make this tax scheme less advantageous for the richer region. Similarly, the effects of the average incomes in the two regions are countervailing.

Scenario (iv) In this scenario (of secession) $N_{\mathrm{a}}=N_{\mathrm{b}}=2$ and public goods are both financed locally. Thus the total cost for the two public goods in jurisdiction 1 is $c^{1}=k_{a}+k_{b}+B\left(\gamma_{a}+\gamma_{b}\right)$ which has to be financed through taxes. Consequently the tax rate in jurisdiction 1 will equal $t^{1}=\frac{k_{a}+k_{b}+B\left(\gamma_{a}+\gamma_{b}\right)}{\overline{y^{1}} B}$.

Comparing again this tax rate to the one obtained in scenario (iii) suggests that secession makes jurisdiction 1 better off than decentralized taxation if

$$
\frac{k_{a}+\gamma_{a}}{\bar{y}}+\frac{k_{b}+\gamma_{b} B}{\overline{y^{1}} B}>\frac{k_{a}+k_{b}+\left(\gamma_{a}+\gamma_{b}\right) B}{\overline{y^{1}} B}
$$

or after some straightforward simplifications: 


$$
\frac{k_{a}+\gamma_{a}}{\bar{y}}>\frac{k_{a}+\gamma_{a} B}{\overline{y^{1}} B}
$$

After simplifying and since $k_{a} \overline{y^{1}}+\gamma_{a} \overline{y^{1}}-\gamma_{a} \bar{y}>0$ it follows that

$$
B>\frac{k_{a} \bar{y}}{k_{a} \overline{y^{1}}+\gamma_{a}\left(\overline{y^{1}}-\bar{y}\right)}
$$

If no income differences exist, (i.e. $\overline{y^{1}}=\bar{y}$ ) then equation (9) shows that $\mathrm{B}$ has to exceed 1 to make secession profitable from a pure tax rate perspective. As income differences appear, however, secession becomes attractive for the richer jurisdiction compared to decentralized taxation. Again, higher fixed $\left(\mathrm{k}_{\mathrm{a}}\right)$ and varying $\left(\gamma_{a}\right)$ costs for providing good a make secession more attractive even for smaller jurisdiction. (i.e., the required value for $\mathrm{B}$ decreases).

The change in the tax rate from scenario (iii) to scenario (iv) is equal to $\frac{k_{a}+\gamma_{a} B}{\overline{y^{1}} B}-\frac{k_{a}+\gamma_{a}}{\bar{y}}$ in jurisdiction 1, which results in an average change of utility of $k_{a}\left(\frac{1}{B}-\frac{\overline{y^{1}}}{\bar{y}}\right)+\gamma_{a}\left(1-\frac{\bar{y}}{\bar{y}}\right)$ due to the taxes. In parallel, the average disutility from public good a under scenario (iii) for individuals $i \in[A, B]$ is equal to $a_{a} \frac{1-B}{2}+a_{b} \frac{B}{4}$, while it decreases to $a_{a} \frac{B}{2}+a_{b} \frac{B}{4}$ under scenario (iv). Thus, individuals in the richer jurisdiction are on average better off under scenario (iv) if $a_{a} \frac{2-3 B}{4}>k_{a}\left(\frac{1}{B}-\frac{\overline{y^{1}}}{\bar{y}}\right)+\gamma_{a}\left(1-\frac{\overline{y^{1}}}{\bar{y}}\right)$ By the definition of the average incomes the changes in tax rate and average tax paid are always negative, making secession in all cases profitable for the richer region.

In the poorer jurisdiction the tax rate will increase by $k_{a}\left(\frac{1}{\overline{y^{2}}(1-B)}-\frac{1}{\bar{y}}\right)+\gamma_{a}\left(\frac{1}{\bar{y}^{2}}-\frac{1}{\bar{y}}\right)$ This expression is positive, indicating that in the secession scenario, the poorer jurisdiction will be forced to increase its tax rate. Thus the average tax increase will be equal to $k_{a}\left(\frac{1}{(1-B)}-\frac{\overline{y^{2}}}{\bar{y}}\right)+\gamma_{a}\left(1-\frac{\overline{y^{2}}}{\bar{y}}\right)$. At the same time the disutility of good a will decrease from $a_{a} \frac{1+(1-2 B)^{2}}{8(1-B)}$ in scenario (iii) to $a_{a} \frac{1-B}{4}$ in scenario (iv) Thus the disutility decreases by $a_{a} \frac{B^{2}}{4(1-B)}$ which has to offset the increased tax burden of $k_{a}\left(\frac{1}{(1-B)}-\frac{\overline{y^{2}}}{\bar{y}}\right)+\gamma_{a}\left(1-\frac{\overline{y^{2}}}{\bar{y}}\right)$. The effect of the size of the richer region $(B)$ on this inequality depends on the values of $a_{a}$ and $k_{\mathrm{a}}$, while larger $\overline{y^{2}}$ make it more likely that the poorer region also profits from secession.

\subsection{Externalities, Unequal Incomes, Federalism, and Secession}

In Alesina and Spolaore's (2003) model the utility resulting from the provision of public goods comprises a positive term $\mathrm{g}$ and negative term $-a_{\mathrm{j}} \mathrm{l}_{\mathrm{i}}$ reflecting heterogeneity in preferences (equation (3)) with regard to public good js. Implicit in this formulation is also the fact that each individual only obtains utility from one public good of each type. To allow for spillover effects, the term $g$ has to be decomposed in utility stemming from goods provided in individual $i$ 's jurisdiction, 
and the utility obtained from a public good provided in another jurisdiction. Similarly, the disutility from a public good not corresponding to ones preferences also has to be disaggregated. Thus for the case in which public good $\mathrm{A}$ is produced centrally and public good B decentralized in two jurisdictions individual $i$ 's utility with externalities corresponds to ${ }^{16}$

$$
u_{i}=y_{i}(1-t)+g-a_{a} l_{a i}-a_{b} l_{b i}+e\left(g_{b^{\prime}}-a_{b^{\prime}} l_{b^{\prime}}\right)
$$

where $b^{\prime}$ corresponds to the public good $b$ provided in another jurisdiction and $e$ measures the importance of externalities. In the case of secession and allowing for externalities individual $i$ 's utility would look as follows:

$$
u_{i}=y_{i}(1-t)+g-l_{a i}\left(a_{a}+a_{b}\right)+e\left(g_{a^{\prime}}+g_{b^{\prime}}-l_{a^{\prime} i}\left(a_{a^{\prime}}+a_{b^{\prime}}\right)\right)
$$

where $l_{a i}$ and $l_{a^{\prime} i}$ reflect the distance for both public goods $a$ and $b$, respectively $a l^{\prime}$ and $b$, since they will be produced jointly at the same location. With these changes it is now possible to assess how externalities affect the four scenarios discussed above.

In scenario $(i)$ the average utility in both regions would not be affected, since both public goods are centrally provided. Thus, no externalities appear in this scenario. ${ }^{17}$

In scenario (ii) the local provision of public good $b$ creates externalities for individuals in both regions. In the richer region, each individual's utility changes by $e$ $\left(g_{b^{\prime}}-a_{b^{\prime}} l_{b^{\prime}}\right)$. The average utility change equals $\mathrm{e}\left(g_{b^{\prime}}-a_{b^{\prime}} \frac{1}{2}\right)$. This expression is either positive or negative, depending on the values of $g_{b^{\prime}}$ and $a_{b^{\prime}}$. But neither $B$ nor the income distribution affects these values. Thus the conclusions discussed in the absence of externalities still hold ceteris paribus for the richer region. In the poorer region the changes in individual and average utility are identical, thus the same conclusion holds.

In scenario (iii), since the provision of the two public goods remains unaltered compared to scenario (ii), externalities do not affect the individuals' and average utilities in both regions. Thus, the conclusions discussed above still hold.

Finally, in scenario (iv), the secession scenario, in both regions the individuals'utilities change by $e\left(g_{a^{\prime}}-a_{a^{\prime}} l_{a^{\prime} i}\right)$. As above the average utility change equals $e\left(g_{a^{\prime}}-a_{a^{\prime}} \frac{1}{2}\right)$, which can either be positive or negative, depending on the values of $g_{a^{\prime}}$ and $a_{a^{\prime}}$. Again, neither $B$ nor the income distribution affects these values. This implies that if the externalities are positive, or only slightly negative not to offset the gains from secession in terms of taxes and decreased disutilities, the richer region is still better off under this scenario. If the externalities of public good $a$ are strongly negative, the richer region might be worse off under secession.

For the poorer region the externalities from public good $a$ may offset the utility loss from the tax increases necessary due to secession. If the externalities are not large enough or even negative, then the poorer region will be worse off under all circumstances. 


\section{Discussion and Conclusion}

This simple extension of Alesina and Spolaore's (2003) model suggests that income differences across regions may lead to demands in richer regions for decentralization or even secession. The introduction of income differences into their model suggests that these affect the tax rates perceived under decentralized taxation. These changes in tax rates make particular arrangements for financing and providing public goods more or less attractive. What appeared generally is that in the absence of externalities elements, which make more decentralization more attractive for the richer region, were systematically those, which made this less attractive to the poorer region. Hence, in decentralization the interests of the two regions are likely to be countervailing in the absence of externalities.

Compared to a federal arrangement with decentralized taxation, secession proved to be preferable for the richer region under the assumption of no externalities. The poorer region, however, profits from secession only under particular circumstances, for instance when its average income $\overline{y^{2}}$ is rather large.

These conclusions are only partly affected by considering possible externalities. If the latter are positive (negative), they simply increase the attractiveness of providing public goods locally (centrally). Especially in the case of secession compared to a federal arrangement the effects of spillovers are interesting. If they are sufficiently large and positive, they might ensure that even the poorer region benefits from secessions. If the spillovers are sufficiently large and negative, they might make secession for both regions unattractive. Given that one of the public goods that is provided centrally even in federal systems is security, it is likely that the externalities of this good are negative in a process of secession. If military forces are established in both jurisdictions for providing security, they will also negatively affect security in the respective neighboring region. Thus, it might be this expected negative externality, which might stave off secession.

Given that decentralized taxation is not systematically profitable for the two regions, it might also be the case that centralized taxation might help staving off secession. Since, secession is always profitable for the richer region compared to decentralized taxation in the absence of externalities, centralized taxation might under certain circumstances be a better option than secession.

Thus the extension to Alesina and Spolaore's (2003) model that I proposed in this paper shows that income differences as well as externalities may have considerable effects in the realm of decentralization and secession. However, the extension discussed here in some sense only provides the context for a broader analysis of federal stability. More precisely, Besley and Coate (2003) are right in arguing that only an analysis of political decision-making will allow for a better understanding of the consequences of decentralization and secession.

What the analysis present above suggests is that in the presence of income differences the push toward decentralization and secession becomes more important. Thus, the burden put on institutions allowing to uphold a federal bargain increases. To ensure against secession, however, one might hope on the negative spillover 
effects of public goods mostly provided by nations, and the unattractiveness of secession compared to centralized taxation.

\section{Notes}

1. This paper partly draws on research funded by the Swiss National Science Foundation (Grant No. 5004-0487882/1). An earlier version entitled "Federalism and the Size of Nations" was presented at the conference "Micro-Foundations of Federal Institutional Stability" at Duke University (Durham, April 30-May 1, 2004). Comments by participants at this conference and greatly appreciated. First version: March 2004, this version: November 1, 2004

2. This position is also discussed in the report by the Section for peace and Reconciliation Norwegian Ministry of Foreign Affairs (2003).

3. While McGarry and O'Leary (2003) discuss federal arrangements proper, Gurr (2000) argues that autonomy arrangements have mitigated many societal conflicts and civil wars. Autonomy arrangements, however, are hardly any different from arrangements of asymmetric federalism.

4. Dudley (2004) offers a stimulating and interesting review of this book.

5. This finding obviously also stands in some contrast to Elazar's (1985) view on federalism and consociationalism.

6. Lijphart (1999) briefly discusses the most important work in this area.

7. Related to this point is the discussion of federalism by Bueno De Mesquita et al. (2003) in the context of their selectorate theory.

8. This obviously under the assumption that even in centralized systems particular public goods may be destined exclusively to specific regions.

9. Alesina and Spolaore $(2003,60 \mathrm{ff})$ discuss briefly the implications of polarization, but refrain from developing this idea in more detail.

10. Le Breton and Weber (2001) provide a nice illustration for this when depicting the fiscal capacity of the German Länder. Similarly, the fact that "greed" and lootable resources appear closely related to civil wars (e.g., Collier et al. 2003) underpins this point.

11. This equation differs only in the first term compared to Alesina and Spolaore (2003), where it would correspond to $\bar{y}-t$.

12. When more than one public good is provided, $g$ represents the overall utility of all provided public goods.

13. Two public goods are required to allow for a federal system according to Riker's (1964) definition. This case is also employed by Alesina and Spolaore (2003) in their analysis of federalism.

14. This scenario addresses Besley and Coate's (2003) point that even in a centralized system the provision of public goods may differ across the territory.

15. My hunch is that this is not a constraining assumption, since I only need differences in average incomes for the results that follow.

16. This formulation follows in part Besley and Coate's (2003) assumptions.

17. Obviously, I abstract here from the fact that the two regions are neighbors to other regions and nations. These externalities, however, remain constant across all the scenarios discussed here and thus do not affect the conclusions.

\section{References}

Alesina, A. and Spolaore, E. (2003) The Size of Nations. Cambridge: MIT Press.

Bednar, J. (1997) Federalisms: Unstable by Design. Los Angeles: U.S.C. Law School.

Bednar, J. (2004) "Judicial Predictability and Federal Stability: Strategic Consequences of Institutional Imperfection." Journal of Theoretical Politics 16(4): 423-46. 
Bednar, J., Eskridge, W. and Ferejohn, J. (2001) A Political Theory of Federalism In: John, Ferejohn. Rakove, Jack, and Riley, Jonathan (eds.) Constitutions and Constitutionalism. pp 223-67. Cambridge: Cambridge University Press.

Besley, T. and Coate, S. (2003) "Centralized versus Decentralized Provision of Local Public Goods A Political Economy Analysis." Journal of Public Economics 87(12): 2611-37.

Bolton, P. and Roland, G. (1997) "The Breakup of Nations A Political Economy Analysis." The Quarterly Journal of Economics 112(4): 1057-90.

Bordignon, M. and Brusco, S. (2001) “Optimal Secession Rules.” European Economic Review 45: 1811-34. Bueno Mesquita, B.De, Smith, A., Siverson, R. M. and Morrow, J. D. (2003) The Logic of Political Survival. Cambridge: MIT Press.

Collier, P., Elliott, L., Hegre, H., Hoeffler, A., Reynal-Querol, M. and Sambanis, N. (2003) Breaking the Conflict Trap. Civil War and Development Policy. New York: World Bank and Oxford University Press.

Dudley, L. (2004). "Review of Alberto Alesina and Enrico Spolaore The Size of Nations." Economic History Services p. URL : http://www.eh.net/bookreviews/library/0734.shtml.

Elazar, D. J. (1985) "Federalism and Consociational Regimes." Publics: The Journal Of Federalism 15(2): $17-34$.

Filippov, M., Ordeshook, P. and Shvetsova, O. (2004) Designing Federalism: A Theory of Self-Sustainable Federal Institutions. Cambridge: Cambridge University Press.

Gurr, T. R. (2000) "Ethnic Warfare on the Wane." Foreign Affairs 79(3): 52-65.

Hicks, U. K. (1978) Federalism:failure and Success: a Comparative Study. London: Macmillan.

Kollman, K. and Page, S. E. (1997) Consequences of Political Instability in a Federal System. Florence: Paper prepared for European Forum.

Le Breton M., and Weber, S. (2001). "The Art of Making Everybody Happy: How to Prevent a Secession." IMF Working Papers 01/176, International Monetary Fund, 2001.

Lijphart, A. (1999) Patterns of Democracy: Government Forms and Performance in Thirty-Six Countries. New Haven: Yale University Press.

McGarry, J., and O'Leary, B. (2003). "Federation, Conflict-Regulation and National and Ethnic PowerSharing." Paper presented at the annual meeting of the The American Political Science Association Philadelphia Mariott Hotel, Philadelphia, PA, 2003-08-27 2003-09-05.

Ordeshook, P. C. and Shvetsova, O. (1997) "Federalism and Constitutional Design." Journal of Democracy 8(1): 27-42.

Riker, W. H. (1964) Federalism: Origin, Operation, Significance. Boston: Little, Brown.

Riker, W. H. (1996) European federalism. The lessons of past experience In: Joachim, Jens Hesse., and Wright, Vincent (eds.) Federalizing Europe? The Costs, Benefits, and Preconditions of Federal Political Systems. pp 9-24. Oxford: Oxford University Press.

Section for Peace and Reconciliation Norwegian Ministry of Foreign Affairs. (2003). "Workshop on Autonomy Arrangements and Internal Territorial Conflicts." Oslo, 14-15 November 2003 Final Report. Watts, R. L. (1998) "Federalism, Federal Political Systems, and Federations." Annual Review of Political Science 1: 117-37.

Young, R. (1998) Games of secession In: Newman, P. (eds.) The New Palgrave Dictionary of Economics and the Law. pp 183-88. London: Macmillan Reference. 